\title{
A Simplified Numerical Method for Blast Induced Structural Response Analysis
}

\author{
Jun $\mathrm{Li}^{*}$, Hong $\mathrm{HaO}^{2}$ \\ 'School of Civil, Environmental and Mining Engineering, \\ the University of Adelaide \\ ${ }^{2}$ School of Civil and Mechanical Engineering, Curtin University
}

Received on 20 Nov 2013, Accepted on 22 July 2014

\begin{abstract}
Efficiently and accurately predicting structural dynamic response and damage to external blast loading is a big challenge to both structural engineers and researchers. The conventional numerical treatment to this problem is proved being able to give reliable predictions, however at the cost of enormous computational time and resource. Simplified SDOF approach is popularly used in design as it is straightforward to use and also gives good structural response predictions if the response is governed by a global response mode (shear or bending) and the accurate dynamic deflection curve is available, but it cannot predict the detailed local structural damage. In this study, a new numerical approach that combines the recently proposed two-step method and the static condensation method is proposed to analyze structure response and collapse to blast loads. The two-step method divides the structural response into two phases, i.e. forced vibration phase (blast loading duration) and free vibration phase. Single- Degree-of-Freedom system approach is adopted to solve the structural element responses at the end of the forced vibration phase, and the structural free vibration simulation is carried out using the hydro-code LS-DYNA to calculate the detailed structural response and damage. The static condensation technique is utilized to condense structural components that are relatively away from the explosion center to further reduce the computational effort. To demonstrate the proposed method, the structural responses of a three story RC frame to blast loads are calculated by four approaches, i.e. the traditional detailed FE simulation, the two-step method, the model condensation method, and the new combined two-step and dynamic condensation method. Through the results comparison, the efficiency and accuracy of the proposed combined approach are demonstrated.
\end{abstract}

Key words: Frame structure, Numerical simulation, Model condensation, Progressive collapse

*Corresponding author. Email address: j.li@adelaide.edu.au 


\section{INTRODUCTION}

In many urban areas around the world, the buildings might be subjected to the threats from the accidental or intentional explosions. The unregulated traffic can bring the terrorism threat within the perimeter of the building. Structural system malfunction and occupant misuse such as the gas leakage can expose the structures to extreme loading conditions. In recent several decades, with more and more high rise buildings erected in modern cities, another important yet disastrous structural response, i.e. the progressive collapse has becoming a major concern for structure engineers. Increasingly more research work has been conducted to investigate the structural response under the blast loading conditions.

Experimental study [1-5] on this topic can provide useful information for reproducing the blast scenario and capturing the damage. However, experiments involving blast loads are always expensive and can even be prohibitive due to the safety concern.

Theoretical methods such as the Mindlin elastic plate theory [6], and Timoshenko beam model [7], can provide valuable information for locating the damage and establishing damage criteria for structural components. However, these methods are based on idealized structural models and are difficult to be applied to complex blast loading and structure conditions.

Recently, computer based finite element method has been widely adopted to simulate the dynamic structural response. It has been proved that this is a reliable means to predict the structural response under blast loads. With computer hydro-code AUTODYN [8], Luccioni et al. [9] analyzed the collapse of an actual building suffering terrorist attack, the structure components such as the beams, columns and plates are modeled with 3D solid elements, the whole blast loading scenario was reproduced in the analysis and the simulation results are validated with the real structural damage. Zhou et al. [10] developed a numerical model to predict concrete slab responses to blast loads. The numerical predictions were found well predicting response and damage of concrete slabs in field blast testing. $\mathrm{Xu}$ and $\mathrm{Lu}$ [11] developed a 3D concrete plate model in LS-DYNA [12] to study its spalling process under explosive loads, and the numerical results show favorable agreement with the existing experiment data. Azrul and Hao developed numerical models to predict RC column [13] and slab [14] with or without FRP strengthening to blast loads. The numerical predictions are also compared with field blasting test data and very good agreements were observed. Hao et al. [15] performed numerical simulations of two-story three-bay reinforced concrete frame buildings to different blast loadings and found that both the GSA [16] and DoD [17] provisions do not necessarily generate the true stress and strain states within the structural members. To address this issue, Shi et al. [18] proposed a new numerical method which includes the effects of blasting scenario in the progressive collapse analysis, thus improves the "member-removal" approach defined in GSA and DoD provisions. Numerical method is also used to simulate bridge responses and collapse to blast loads under different explosion scenarios $[19,20]$. Recently a discussion on various engineering (based on SDOF model) and numerical tools (Hydro-code) for analysis of RC structure responses to blast loads has been presented by Riedel et al. [21].

As reviewed above, the numerical method is a relatively easy-to-use method, and it can provide reliable structural response predictions. However, such method has its own limitations. It has been noticed that for highly nonlinear dynamic problems such as structural response to blast or impact loads, in order to get reliable simulations and capture local damage, refined mesh is required, which makes the simulation extremely resource and time consuming. In the cases of simulation of multistory frame structures or large span bridges to blast loadings, it could even be an impossible task owing to the extreme demanding on computer power. 
To reduce the analysis effort and difficulty, in practice, the structural components are often simplified into a Single-Degree-of-Freedom (SDOF) system for analysis. Krauthammer [22] simplified a reinforced concrete slab to an equivalent SDOF system and analyzed its response and failure to blast loads. For reinforced concrete beams and one-way slabs under the blast loading condition, Krauthammer et al. [23] developed a step-by-step analytical method based on the SDOF model and considered the material nonlinearities in the structure dynamic analysis. Although the SDOF model is an effective method to calculate the structural response under blast load, it is commonly recognized that its prediction accuracy very much depends on the response mode of the structure. If the structural response is governed by a global mode such as a shear or a bending response mode, the approach can lead to accurate predictions. If the structural response is governed by combined modes or localized responses, such as concrete crushing and spalling owing to stress wave propagation, the SDOF approach might not give good predictions. Moreover, it is often difficult to define a good damage criterion based on the responses of the SDOF system.

To overcome the above discussed problems in SDOF analysis and the complex and resource demanding numerical simulations, recently, Hao [24] proposed a method that combines the SDOF analysis and numerical simulation to predict structural responses to blast loads. It is based on the assumption that the structural displacement response and damage is very small in the forced vibration phase because blast loading duration is very short as compared to the vibration period of most structures such that there is no sufficient time for overall structural response to develop, and large displacement response and damage only occur in the free-vibration phase. Therefore the structural response is calculated in two steps. In the first step, the structural velocity response at the end of the blast loading duration is calculated, which is used as the initial condition in the second step free-vibration analysis with detailed finite element model to predict structural response and damage. Because only free-vibration analysis is modeled in detail, relatively large element sizes and hence large integration time step can be used in the second-step free vibration analysis, leading to substantial savings on computer memory and computational time. The method is proven leading to reliable predictions of structural response if the response is governed by the flexural mode that the displacement response is small and no occurrence of brittle damage during the blast loading duration. However, it might significantly underestimate structural response and damage if the response is governed by shear mode and brittle damage occurs in the structure during the blast loading stage [25]. The method is subsequently improved by including displacement response at the end of the blast loading phase as the initial conditions [25], and further improved by including the influences of brittle damage occurred during the blast loading phase on structural stiffness and strength reductions in the second step freevibration analysis [26]. It is proven that the improved two-step method can give reliable predictions of structural component response and damage to blast loads. This two-step method may lead to more than $90 \%$ savings in computational time as compared to the direct FE simulations.

It has been reported that the blast scenario-independent member removing approach does not necessarily lead to accurate predictions of structural progressive collapses [15]. To better predict structural progressive collapse, intensive researches have been carried out. An improved member- removing method that avoids time-consuming direct FE model simulation while includes the damage that might be induced in adjacent structural members by blast loading before progressive collapse initiates has been proposed [18]. More recently, the static condensation method is also proposed to save computational cost in predicting structural progressive collapse to blast loads [27]. Static condensation (Guyan reduction) is 
a classic method in FE element simulation of structural responses to save the computational effort [28]. For a typical FE model of a real structure, the structure is meshed into a large number of elements according to structure geometry, loading condition and material properties, the number of unknown displacements, i.e. the number of DOFs, can be very large. As a consequence, the stiffness, mass and damping matrices have large dimensions. These huge matrices make the calculation of structural response extremely time consuming. It is therefore desirable to reduce the size of these matrices in order to make the calculation more manageable and economical. During static condensation process, the structure finite element model is manually partitioned into two node sets, i.e. the master node set and the slave node set. Since there is no direct force loaded on the slave nodes, it is possible to temporarily eliminate the slave nodes through creating an equivalent element relation to link them with the master nodes. For structures under blast loads, severe blast loading effects are usually limited to a local area and progressive collapse also only occurs in a certain part of the structure. This makes the static condensation especially attractive in analyzing structure response and progressive collapse to blast loads. The recent study of using static condensation method in reducing the structural model and predicting structural response and progressive collapse to blast loads demonstrates that the method gives good predictions of structural response, damage and progressive collapse at only a fraction of computational time as compared to the direct FE simulations [27].

This paper explores the possibility of combining these two recently proposed time-saving methods, i.e., the two-step method [25] and the model condensation method [27], to further improve the efficiency of numerical simulations of structural responses and progressive collapse to blast loads. In this new combined approach, the response of structural columns close to the explosion center during the loading phase will be calculated using the SDOF analysis [25], the damage of the respective columns at the end of blast loading duration will be assessed according to the analytical Pressure-Impulse curves obtained in [26]. The overall structure will be condensed through static condensation procedure and the second-step free vibration analysis will be conducted on the condensed structural model to predict response and possible progressive collapse of the structure. To demonstrate the proposed method, a three-story RC frame structure subjected to blast loads is analyzed. For comparison, the response and progressive collapse of this example frame structure are also calculated by three other methods, i.e. the direct simulation with the FE model of complete structure, which is considered as bench mark simulation to compare the efficiency and accuracy of the proposed method, two-step method and the model condensation method. Numerical results obtained from all these approaches are compared. The efficiency and accuracy of the proposed method in predicting structural damage and progressive collapse to blast loads are demonstrated.

\section{INITIAL CONDITION DERIVATION}

\subsection{BLAST SCENARIOS CONSIDERED IN THIS STUDY}

Without losing generality, in the present study, the blast loads are applied to the columns only. This is because the RC floors in a frame structure have high in-plane stiffness and large mass, the transverse direction responses of the beams and slabs are relatively small as compared to those of columns. Moreover the vertical blast loads from blast waves travelling into the open frame deck that cause uplifting of frame structure [29] are not considered in the simulation either. This is a reasonable assumption because nonstructural members such as partition walls and glazing, which are not included in the numerical model, will significantly reduce the blast wave traveling into the structure to uplift the frame 
In this study, two blast loading scenarios are considered. In the first case study, the frame structure survives the blast loads without collapse. In the second case study, structural progressive collapse initiates under the specified blast loads.

\subsection{INITIAL DISPLACEMENT AND VELOCITY DERIVATION}

According to Biggs [30], structural component can be simplified into an equivalent SDOF system for analysis by following certain deformation shape. The accuracy of the SDOF method largely depends on the deformation shape assumption. In a previous study [25], it is demonstrated that when blast loading duration is short as compared to the vibration period of the structure, shear deformation assumption leads to a more accurate prediction of structural responses. With the increase of the blast loading duration, the accuracy of the shear deformation assumption deteriorates while the flexural deformation shape gives better prediction of the structural response. In the present study, without losing generality, a diagonal shear deflection shape is assumed for columns to derive the equivalent SDOF system.

The shape function for columns is defined as follows in Figure 1:

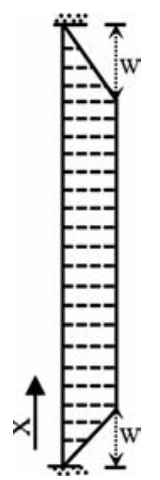

$$
\varphi(x)= \begin{cases}\frac{x}{w} & x \in(0, w) \\ 1 & x \in(w, L-w) \\ \frac{L-x}{w} & x \in(L-w, L)\end{cases}
$$

\section{Figure 1. Assumed deflection shape and equation}

Using this shape function, the equivalent SDOF system for a given column under uniformly distributed blast loading can be straightforwardly derived [25, 26]. Assuming zero initial conditions, i.e., $U_{t=0}=0, V_{t=0}=0$, the displacement and velocity response of the equivalent SDOF system in the loading phase, $t \leq t_{d}$, can then be derived as

$$
\begin{aligned}
& U(t)=\frac{p_{e}}{K_{e}}\left(1-\frac{t}{t_{d}}-\cos \omega_{n} t+\frac{\sin \omega_{n} t}{\omega_{n} t_{d}}\right) \\
& V(t)=\frac{p_{e}}{K_{e}}\left(\frac{\cos \omega_{n} t-1}{t_{d}}+\omega_{n} \cos \omega_{n} t\right)
\end{aligned}
$$

where td is the blast loading duration, $\mathrm{U}(\mathrm{t})$ and $\mathrm{V}(\mathrm{t})$ are displacement and velocity responses, $\mathrm{Pe}$ is the equivalent peak blast load, and $\omega$ n is the natural vibration frequency of the equivalent SDOF system. Substituting $t=t_{d}$, the response of the equivalent SDOF system at the end of the blast loading duration can be easily derived, which are then used as the initial conditions in the second step free-vibration analysis. More detailed descriptions of SDOF parameter derivation and application of the derived displacement and velocity of the SDOF system at the end of blast loading duration to the structural model as initial conditions for free vibration analysis can be found in [25]. 


\subsection{INITIAL DAMAGE DERIVATION}

According to previous discussions by Hao et al. [15] and Shi et al. [18], damage induced by blast load to the adjacent structural components as well as the target columns plays an important role in structural collapse simulation. Although progressive collapse and blast loading are usually not coupled, i.e., progressive collapse occurs only after the action of blast loading, it does not start from zero initial condition because blast loading might impart significant amount of energy into the structure. Therefore the blast scenario independent approach that removes only the target columns while assuming adjacent structural components remain intact with zero initial conditions when progressive collapse occurs may not lead to reliable predictions. In this study, the damage at the end of blast loading duration is assessed and introduced into the structural model in the second step free vibration analysis.

Evaluation of structural damage to blast load has been conducted extensively [31], [32], [33], [34]. The damage criteria of these studies are mostly deformation based such as the maximum deflection to span length ratio and support rotation. These criteria correlate well with structural damage when the damage is governed by flexural response. They cannot well define shear response dominated damage and cannot capture the local damage modes of structural components under blast loading condition. Recently, a numerical study concerning the blast induced damage to $\mathrm{RC}$ beams at the end of blast loading duration was conducted by Li and Hao [26]. In that study, a criterion based on the shear slip proposed by Krauthammer [22] was utilized and intensive parametric study was carried out. Analytical formulae for generating the Pressure-Impulse (P-I) curves to predict RC structural component damage at the end of blast loading duration were proposed. These P-I curves can be used to quickly assess the blast induced damage at the end of blast loading duration. They were used to model brittle structural damage in the two-step method to predict structural responses [26].

It should be noted that these formulae were derived to predict brittle damage of RC beams induced in the blast loading duration, they are used in the present study to predict brittle damage of RC columns. The difference between a beam and a column is the existence of axial force in the column and this axial force interacts with bending moment to influence the column performance. The most critical influence of axial force is the secondary P- $\Delta$ effect. However, the P- $\Delta$ effect depends on the column deformation modes. Under blast loading condition, since the blast loading duration is very short compared to the column vibration period, column displacement response will be very small during the blast loading duration. Therefore the influence of axial force in the column on brittle shear damage at the end of blast loading duration is expected insignificant. For these reasons, the previously derived PI diagrams to predict brittle shear damage of RC beams [26] are used in the present study to approximately predict the damage in RC columns.

In order to relate the damage to the material in the $\mathrm{RC}$ member, two assumptions are adopted. Firstly, since the deflection in the steel reinforcement at the end of extremely short blast loading duration is quite small, and the reinforcement undergoes the elastic response, only the damage to the concrete material in the blast loading phase is assumed. Secondly, the damage of the RC component is assumed to be located within damage zones along the column height. The damage zone location varies for different damage modes. In this study, the analytical formulae given in [26] is utilized to predict the shear damage zone length.

The damaged concrete compressive strength and Young's modulus are defined by [26]

$$
f_{c \text {-damaged }}^{\prime}=f_{c}^{\prime}(1-D) ; E_{\text {damaged }}=E(1-D)
$$

where $D$ is the damage scalar that can be easily predicted from P-I diagrams derived in [26]. 


\section{STATIC CONDENSATION}

In finite element simulation, in order to reduce a finite element model to a smaller size to acquire better efficiency, model reduction techniques such as static condensation proposed by Guyan [28] are widely adopted. The main idea of condensation is described below.

Considering a 3D structure model which is properly constrained and loaded, the number of degrees of freedom equals to $6 \mathrm{n}-\mathrm{c}$ ( $\mathrm{n}$ is the number of nodes, $\mathrm{c}$ is the number of constrains). The equilibrium equation in matrix form is

$$
[M] \times[\ddot{u}]+[C] \times[\dot{u}]+[K] \times[u]=[F]
$$

where $M, C$ and $K$ represent the mass, damping and stiffness matrices, $u$ and $F$ denote the displacement and external force vector. The nodes in the model can be manually divided into two sets, i.e. the "master" set and the "slave" set. Then Equation 5 can be partitioned and expressed as

$$
\left[\begin{array}{l}
M_{m m} M_{m s} \\
M_{s m} M_{s s}
\end{array}\right] \times\left[\begin{array}{l}
\ddot{u}_{m} \\
\ddot{u}_{s}
\end{array}\right]+\left[\begin{array}{ll}
C_{m m} C_{m s} \\
C_{s m} C_{s s}
\end{array}\right]\left[\begin{array}{l}
\dot{u}_{m} \\
\dot{u}_{s}
\end{array}\right]+\left[\begin{array}{l}
K_{m m} K_{m s} \\
K_{s m} K_{s s}
\end{array}\right]\left[\begin{array}{l}
u_{m} \\
u_{s}
\end{array}\right]=\left[\begin{array}{l}
F_{m} \\
F_{s}
\end{array}\right]
$$

where. $M_{m m}, C_{m m}, K_{m m} \in R^{m \times m} ; M_{m s}, C_{m s}, K_{m s} \in R^{m \times s} ; M_{s m}, C_{s m}, K_{s m} \in R^{s \times m} ; M_{s s}, C_{s s}, K_{s s} \in R^{s \times s}$; $M_{s s}, C_{s s}, K_{s s}, \in R^{s \times s}, F_{m}$ and $F_{s}$ denote the external force applied on the master degrees of freedom and slave degrees of freedom.

Expanding the second equation in the partitioned Equation 6 gives

$$
M_{s m} \ddot{u}_{m}+M_{s s} \ddot{u}_{s}+C_{s m} \dot{u}_{m}+C_{s s} \dot{u}_{s}+K_{s m} u_{s}+K_{s s} u_{s}=F_{s}
$$

Because the condensation matrix is a natural property of the system and does not depend on the external force, by selecting the part of structure that is not under direct blast loading as the slave nodes, the external force on the slave degrees of freedom is zero. In order to get the condensed mass, stiffness and damping matrix, first letting

$$
\ddot{u}_{m}=\dot{u}_{m}=0 ; \ddot{u}_{s}=\dot{u}_{s}=0
$$

in Equation 7 and rearrange it results in

$$
u_{s}=R_{D} u_{m}
$$

where $R_{D}=-K_{s s}^{-1} K_{s m}$ is the condensation matrix defined in displacement space.

Differentiating both sides of Equation 9 with respect to time yields

$$
\dot{u}_{m}=R_{D} \dot{u}_{m}, \ddot{u}_{s}=R_{D} \ddot{u}_{m}
$$

Substituting Equations 9 and 10 into Equation 6, and then premultiplying both sides by matrix $\left[\begin{array}{ll}I & R_{D}^{T}\end{array}\right]$, where $I$ is an identity matrix, results in

$$
M_{c o n} \ddot{u}_{m}+C_{c o n} \dot{u}_{m}+K_{c o n} u_{m}=F_{m}
$$

The reduced mass matrix $M_{\text {con }}$, damping matrix $C_{\text {con }}$ and stiffness matrix $K_{\text {con }}$ are then derived as

$$
\begin{gathered}
M_{c o n}=M_{m m}-K_{m s} K_{s s}^{-1} M_{s m}-M_{m s} K_{s s}^{-1} K_{s m}+K_{m s} K_{s s}^{-1} M_{s s} K_{s s}^{-1} K_{s m} \\
C_{c o n}=C_{m m}-K_{m s} K_{s s}^{-1} C_{s m}-C_{m s} K_{s s}^{-1} K_{s m}+K_{m s} K_{s s}^{-1} C_{s s} K_{s s}^{-1} K_{s m} \\
K_{c o n}=K_{m m}-K_{m s} K_{s s}^{-1} K_{s m}
\end{gathered}
$$


This method has been successfully incorporated with numerical simulation to predict the structural progressive collapse [27]. In the present study, this technique is also utilized and the mass as well as the stiffness are condensed. This is proved to be more accurate when solving the structural response under blast loads because the inertia force plays an important role under this kind of loading conditions.

\section{THE PROPOSED METHOD}

In the proposed method, the blast loading induced structural response is calculated in two stages. Firstly, the structural response during the blast loading phase is calculated through the SDOF model to derive the maximum deflection and velocity of the structural components at the end of the blast loading phase. The induced damage of structural components in the blast loading phase is assessed according to analytical P-I curves given in [26]. In the second step, the calculated responses at the end of the blast loading phase are used as initial conditions to perform free- vibration analysis. Detailed FE model is developed in LS-DYNA for free-vibration analysis because structural damage and progressive collapse are simulated in this step. However, compared to direct FE simulations, less refined meshing size is used. The condensation algorithm is conducted to decrease the size of the structure stiffness and mass matrix, only the components close to the blast are modeled in the simplified method, and the other components are condensed into a single super element [27].

The detailed procedure of this method is described as follows.

a) Establish the FE model in ANSYS LS-DYNA.

b) Calculate the blast loads and duration on target columns. Using the equivalent SDOF model to calculate the displacement and velocity at the mid-span of the column at the end of the blast loading duration.

c) Estimate the column damage severity at the end of blast loading duration, and modify the concrete material modulus and strength in the damaged zone according to the damage level.

d) Using the static condensation to condense the structure mass and stiffness matrix.

e) Conducting the second-step free vibration analysis of the condensed structural model with the displacements and velocities from Step (b) as initial conditions.

In the proposed simulation, the initial displacement is applied with *boundary prescribed_motion in LS-DYNA, and a Dynamic Relaxation is utilized to initialize the structure with the prescribed deformation. The initial velocity is applied explicitly on the structure to conduct the free vibration analysis through *initial_velocity_generation.

\section{CASE STUDY}

To demonstrate the proposed method, a three-story RC frame structure as shown in Fig. 2 under blast loading is analyzed. This three-story RC structure has two bays with a span of $3 \mathrm{~m}$ each in the $\mathrm{x}$ direction, and two bays with a span of $6 \mathrm{~m}$ each in the $\mathrm{y}$ direction. The story height is $3 \mathrm{~m}$ for all levels. The dimensions of all the columns are $300 \mathrm{~mm} \times 300 \mathrm{~mm}$, and the beams are $300 \mathrm{~mm} \times 400 \mathrm{~mm}$. The longitudinal reinforcement ratio for columns and beams are $1.5 \%$ and $0.6 \%$ respectively. The concrete has uniaxial compressive strength of $40 \mathrm{MPa}$. The yield stress for the steel is $335 \mathrm{MPa}$. The slab is $100 \mathrm{~mm}$ thick with a dimension of $6 \mathrm{~m} \times 3 \mathrm{~m}$, the reinforcement in the slab is not modeled in detail in this study. 

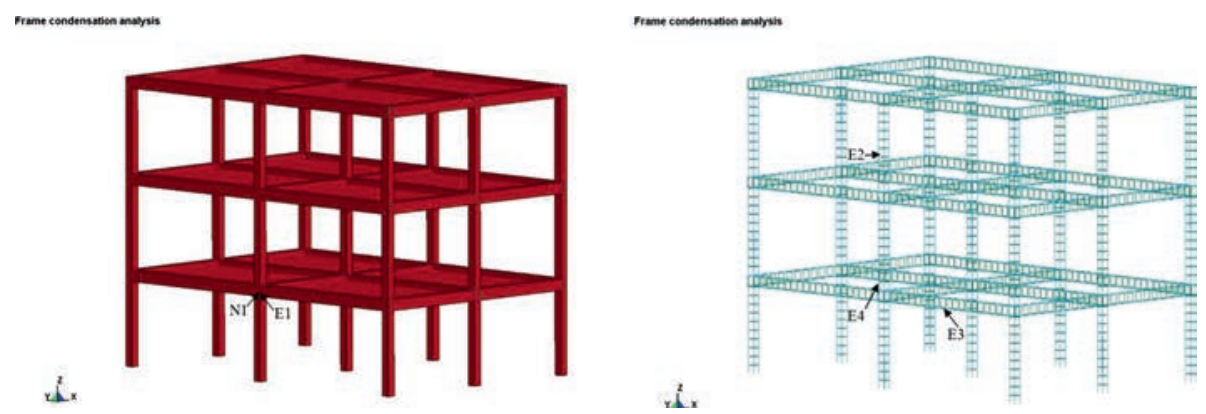

Figure 2. Frame structure FE model, a) example RC frame, b) reinforcement mesh

Solid element with single integration point is used to model the concrete, and beam element is used to simulate the steel reinforcement. In the benchmark simulation, i.e., direct FE simulation, the mesh size for the concrete and beam element is $50 \mathrm{~mm}$. According to convergence test, if further decreasing the element size, the increase of the simulation accuracy is limited, however at a cost of much longer calculation time. In the simplified twostep method, the simulation of the structural free vibration does not require a very small element size [25], thus the mesh size is increased to $100 \mathrm{~mm}$ which doubles that used in the direct simulation.

The material model MAT_CONCRETE_DAMAGE_REL3 ('MAT_72REL3) available in LS- DYNA [12] is used to model the concrete. This model has been used to analyze concrete subjected to impulsive loading successfully [25], [35], [36]. It is found that the RC structure damage simulated by this model fits well with the experimental observations [37].

MAT_PIECEWISE_LINEAR_PLASTICITY ("MAT_024) is use to model the steel, this model allows arbitrary stress versus strain curve and strain rate curve definition. Failure based on a plastic stain can be defined. This material model has been used to successfully simulate the steel under blast or impact loads [25], [26], [35].

The material properties used in the present study are listed in Table 1.

The strain rate effect of the material is taken into consideration in this study. Dynamic Increase Factor (DIF) for the concrete compressive strength is defined according to the

Table 1. Material model used in this study

\begin{tabular}{llll} 
Material & LS-DYNA Model & Input Parameters & Magnitude \\
\hline \multirow{3}{*}{ Concrete } & MAT_CONCRETE_ & & \\
& DAMAGE_REL3 & Concrete strength & $40 \mathrm{MPa}$ \\
& (SOLID 164) & Principle strain & 0.15 \\
& Erosion criteria & Shear strain & 0.9 \\
\hline \multirow{3}{*}{ Reinforcement } & Mass density & $7800 \mathrm{~kg} / \mathrm{m} 3$ \\
& & Elastic modulus & $200 \mathrm{GPa}$ \\
& MAT_PIECEWISE_ & Poisson's ratio & 0.3 \\
& LINEAR_P & Yield stress & $335 \mathrm{MPa}$ \\
& LASTICITY(BEAM 161) & Failure plastic strain & 0.15 \\
\hline
\end{tabular}


empirical function provided by CEB-FIP Model Code 1990 [38], that for the concrete tensile strength is defined according to Malvar and Crawford [39], and that for steel according to Malvar [40]. The empirical equations are given below.

For concrete compressive strength:

$$
D I F=\frac{f_{c}}{f_{c s}}= \begin{cases}\left(\frac{\dot{\varepsilon}}{\dot{\varepsilon}_{s}}\right)^{1.026 \alpha} & \text { for } \dot{\varepsilon} \leq 30 s^{-1} \\ \gamma_{s}\left(\frac{\dot{\varepsilon}}{\dot{\varepsilon}_{s}}\right)^{1 / 3} & \text { for } \dot{\varepsilon} \leq 30 s^{-1}\end{cases}
$$

where $f_{c}$ is the dynamic compressive strength at $\dot{\varepsilon} ; f_{c s}$ is the static compressive strength at is $\dot{\varepsilon}_{s} ; \dot{\varepsilon}$ the strain rate in the range of $30 \times 10^{-6}$ to $300 \mathrm{~s}^{-1} ; \dot{\varepsilon}_{s}$ is the static strain rate $30 \times 10^{-6}$; $\log \gamma_{s}=6.156 \alpha-2 ; \alpha=1 /\left(5+9 f_{c s} / f_{c o}\right) ; f_{c o}=10 \mathrm{MPa}$.

For concrete tensile strength:

For reinforcement:

$$
D I F=\frac{f_{t}}{f_{t s}}= \begin{cases}\left(\frac{\dot{\varepsilon}}{\dot{\varepsilon}_{s}}\right)^{\delta} & \text { for } \dot{\varepsilon} \leq 1 s^{-1} \\ \beta\left(\frac{\dot{\varepsilon}}{\dot{\varepsilon}_{s}}\right)^{1 / 3} & \text { for } \dot{\varepsilon} \leq 1 s^{-1}\end{cases}
$$

$$
D I F=\left(\frac{\dot{\varepsilon}}{10^{-4}}\right)^{\alpha}
$$

where for the yield strength, $\alpha=\alpha_{f y}=0.074-0.04 f_{y} / 60$; and for the ultimate stress, $\alpha=\alpha_{f u}=$ $0.019-0.009 f_{y} / 60$.

In LS-DYNA, some constitutive models such as the SOLID 164 used in this study do not allow failure and erosion, thus in order to simulate the fracture and crushing of the concrete material, the so-called erosion algorithm is implemented. This algorithm has been widely adopted in previous studies to simulate concrete response and damage under blast loading $[11,18,25,35,41]$. In the present study, when the principle strain reaches 0.15 or the shear strain reaches 0.9 , the concrete element will be automatically erased, and the erased element will not provide further resistance. It is worth noting that such an erosion algorithm must be used with caution. A balance must be reached in selecting the erosion criteria. If they are set too low, the massive erosion of the solid elements will breach the conservation of mass and energy, then the simulation results will no longer be reliable.

\subsection{CASE STUDY 1}

\subsubsection{Benchmark simulation}

In the present study, results from direct FE simulations are used as benchmark for comparison to check the accuracy of the proposed method. Table 2 shows the blast loads on the major columns facing the blasting centre. The blast loads on all the other columns, as well as on side walls and roof are neglected. It should be noted that these loads are approximately estimated from UFC [42] based on a blasting scenario of $600 \mathrm{~kg}$ TNT detonated on ground surface $13 \mathrm{~m}$ from the centre column of the frame structure. Since the primary purpose of the study is to demonstrate the proposed method, the blast loads acting on other structural components are neglected in the simulations. 
Table 2. Blast loads and duration on columns

\begin{tabular}{llll} 
& $\begin{array}{l}\text { Middle column of } \\
\text { first floor }\end{array}$ & $\begin{array}{l}\text { Middle column of } \\
\text { second floor }\end{array}$ & $\begin{array}{l}\text { Side columns of } \\
\text { first floor }\end{array}$ \\
\hline Blast load & $2.0 \mathrm{MPa}$ & $1.8 \mathrm{MPa}$ & $1.5 \mathrm{MPa}$ \\
Duration & $6.5 \mathrm{~ms}$ & $7.0 \mathrm{~ms}$ & $7.7 \mathrm{~ms}$ \\
\hline
\end{tabular}

Figure 3 shows the structural response at $\mathrm{t}=7 \mathrm{~ms}$, approximately the end of the blast loading phase. It can be observed that the structure experiences only minor concrete damage.

After the blast loading duration, the structure enters into the free vibration phase. At the end of $0.5 \mathrm{~s}$ the structure reaches a stable status as shown in Figure 4. It can be concluded that only small deformation occurs to the structural components, and the structure survives the specified blasting scenario without collapse. More specific response quantities will be presented and discussed later.

\subsubsection{Model condensation method}

In this section, dynamic condensation is conducted to reduce the finite element model size. As shown in Figure 5, the rear part of the frame structure which locates relatively away from the detonation center and experiences primarily elastic deformation during the free vibration

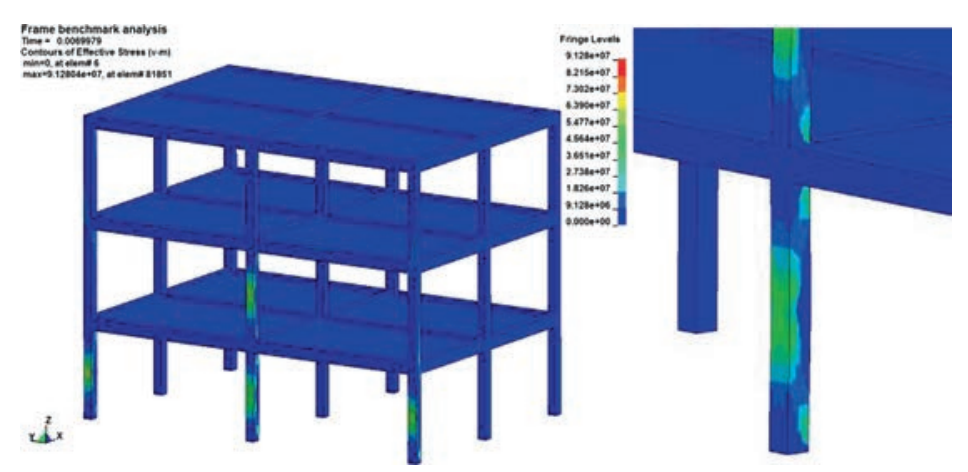

Figure 3. Structural response at the end of blast loading duration

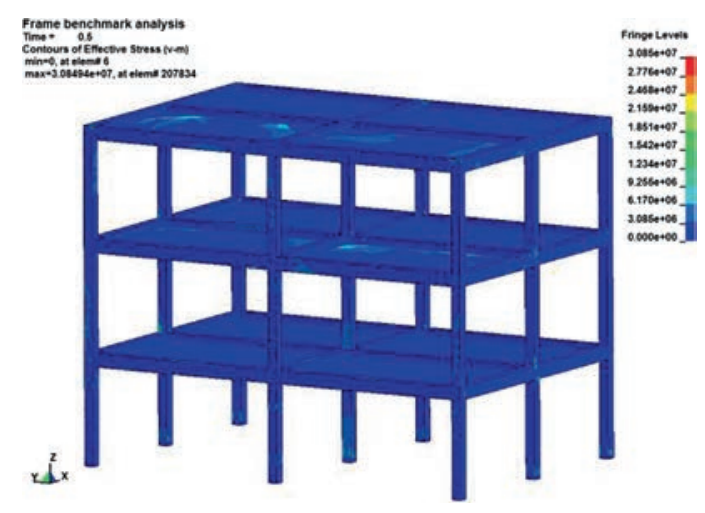

Figure 4. Structural response at $0.5 \mathrm{sec}$ 


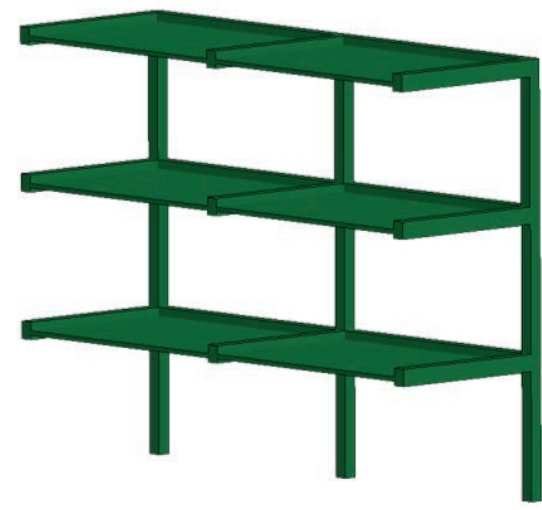

(a) Condensed part

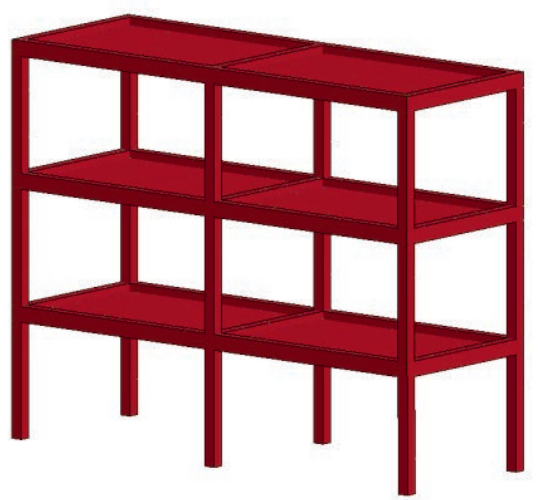

(b) remaining part

Figure 5. Condensed part and remaining part of the FE model

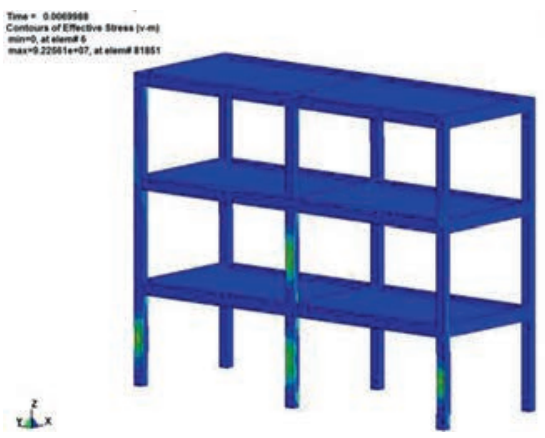

(a) $\mathrm{t}=7 \mathrm{~ms}$

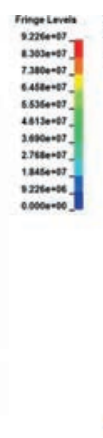

$2 \times$

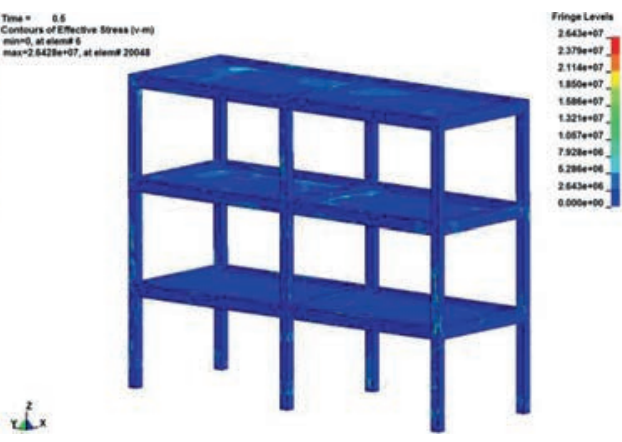

(b) $\mathrm{t}=500 \mathrm{~ms}$

Figure 6. Structural response

duration is condensed. Only the remaining part is modeled in the FE analysis in LS-DYNA. The same blast loads are applied to the remaining structure.

Figure 6 shows the structural response at the end of blast loading duration and at $0.5 \mathrm{sec}$. No clear damage occurs to the structure and all the components remains intact. Similar structural deformation and stress distribution configurations as those shown in Figures 3 and 4 are observed.

\subsubsection{Two-step method}

In this section, the numerical simulation using the two-step method defined in [25] is conducted. Only the free vibration phase is simulated, the mesh size is increased to $100 \mathrm{~mm}$ which doubles the size used in direct simulation.

Using Equations 2-3, the maximum displacement and velocity at mid-span of the columns at the end of blast loading duration can be easily derived from the equivalent SDOF system, then following the deformation assumption defined by Equation 1, the displacement and velocity for each node along the column can be determined. It should be noted that, in FE 


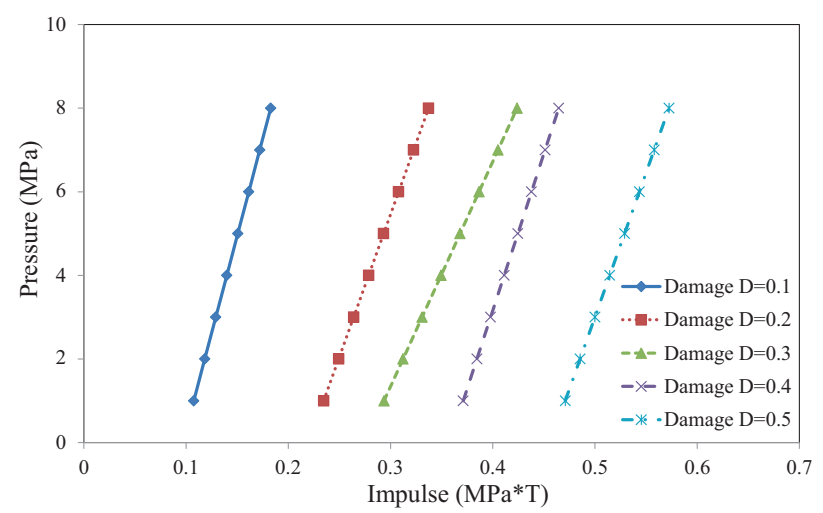

Figure 7. Pressure-Impulse curves for columns (26)

model, it is very time consuming to apply the displacement and velocity to each node along the column height, in this study, the column is divided into 30 segments, each segment shares the same displacement and velocity following the presumed deformation assumption.

P-I curves are generated according to the analytical formulae defined in [26] to estimate the brittle shear damage occurs in the blast loading phase, and they are shown in Figure 7.

In this case study, the blast scenario on the middle column on the ground floor has a pressure of $2.0 \mathrm{MPa}$ with an impulse of $0.3 \mathrm{MPa}^{*} \mathrm{~T}$ ( $\mathrm{T}$ is the natural vibration period of the column and $\mathrm{T}=22 \mathrm{~ms}$ ). From the P-I diagram, a damage level of $\mathrm{D}=0.26$ at the end of blast loading duration can be obtained. Similarly, the damage of the first floor middle column can also be easily obtained. According to analytical formulae derived in [26], the shear damage zone $W$ could be easily determined as $0.8 \mathrm{~m}$.

Once the damage level is determined, in the damage zone the concrete elastic modulus and strength is decreased according to the relationship given in Equation 4.

As shown in Figure 8, after conducting free vibration simulation for up to $0.5 \mathrm{~s}$, the structural response reaches a stable state and structural collapse does not occur.

\subsubsection{Proposed method}

In the proposed method, same initial condition as derived in the two-step method model is introduced, and the dynamic condensation to the structural rear part is conducted. Only the free vibration phase is simulated, and the element size is $100 \mathrm{~mm}$.

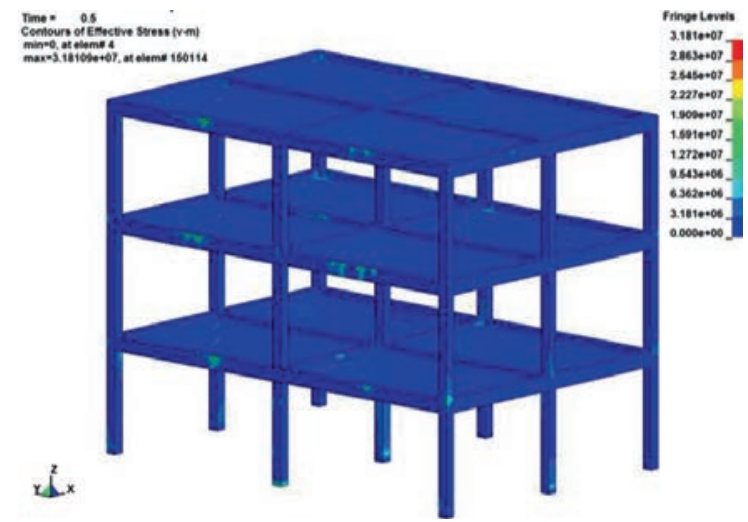

Figure 8. Structural response at $\dagger=0.5 \mathrm{~s}$ 


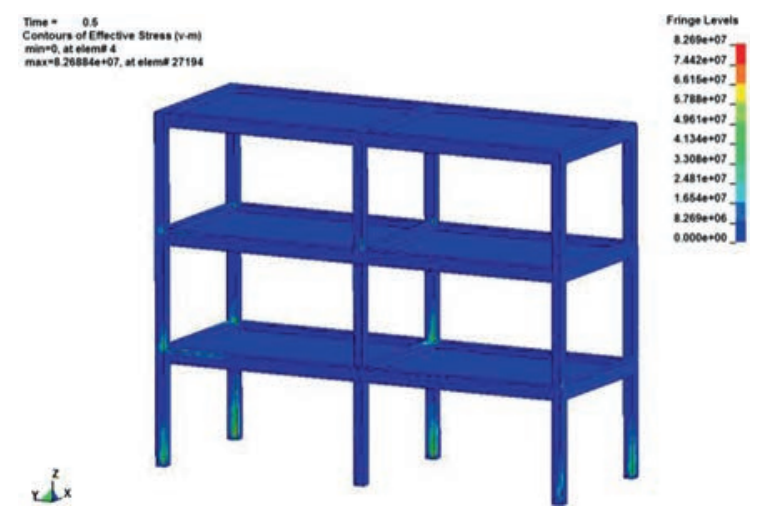

Figure 9. Structural response at $\dagger=0.5 \mathrm{~s}$

After $0.5 \mathrm{~s}$ simulation, the frame structure reaches a stable status as shown in Figure 9. Structural collapse does not occur.

\subsubsection{Proposed method}

The quantitative results from all the methods discussed above are compared with each other. Five quantities at the key nodes and elements of the structural model are extracted from the numerical results and compared with each other. They are:

a) vertical displacement, velocity and acceleration of node N1 defined in Figure 2.

b) effective v-m stress and plastic strain in concrete element E1.

c) axial stress in vertical reinforcement element E2.

d) axial stress in horizontal reinforcement element E3.

e) axial stress in hoop reinforcement element E4.

As shown in Figure 2, N1 is the node at the middle of the beam-column joint above the first- story middle column; E1 is the concrete element locates at the same position as N1; E2 is the beam element that models the vertical steel reinforcement bar at the mid-span of the third floor column; E3 is the beam element that models the horizontal steel bar on the bottom side of the first floor beam; E4 is the beam element that models the stirrup rebar close to the beam-column joint on the first floor.

The vertical displacements at node N1 obtained by the four approaches are shown in Figure 10. It should be noted that the two-step method and the proposed method in this study only simulates the free vibration phase and the initial deformation is derived from the SDOF model, therefore their responses in the graph only starts from the end of blast loading duration.

It can be observed that, all these methods give reasonably similar predictions of the vertical displacement of the structure. All methods predict that the vertical displacement oscillates but stabilizes after a few cycles of vibrations. The condensation method gives the most accurate peak prediction which is around $3.8 \mathrm{~mm}$ as compared to the direct FE simulation. However it underestimates the residual displacement at the end of simulation. The peak values yielded by the two-step method and the proposed method are $2.3 \mathrm{~mm}$ and $2.9 \mathrm{~mm}$, which are slightly smaller than the peak upward displacement obtained from direct FE simulation. However, the two-step method and the proposed method successfully predict the residual displacement which is around $-2.2 \mathrm{~mm}$. It can be noted that the blast load generates a small downward displacement initially, and then a $3 \mathrm{~mm}$ to $4 \mathrm{~mm}$ upward rebound in free vibration phase owing to large blast energy imparted into the structure in the form of initial velocity. Overall the vertical displacement response is very small. 


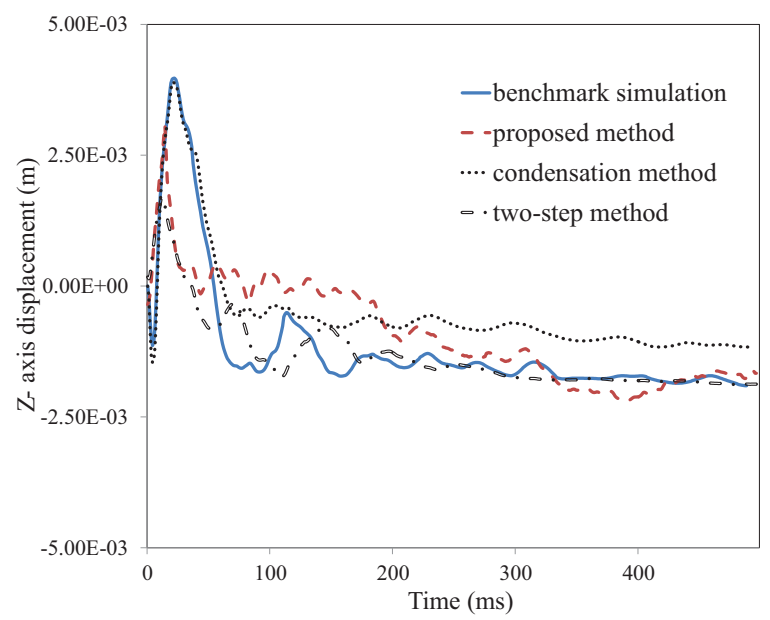

Figure 10. Vertical displacement of N1

Figure 11 shows the vertical velocity and acceleration of the same node N1. As can be noticed, the vertical velocity increases quickly after applying the blast load. After entering the free vibration phase, the energy dissipates in the form of vibration and the inertia force quickly reduces the velocity and acceleration. The maximum velocity predicted by the benchmark simulation is around $0.68 \mathrm{~m} / \mathrm{s}$ and the proposed method gives a value of $0.55 \mathrm{~m} / \mathrm{s}$, the velocity predicted by condensation method and the two-step method are $0.75 \mathrm{~m} / \mathrm{s}$ and $0.36 \mathrm{~m} / \mathrm{s}$ respectively. The maximum acceleration predicted by the benchmark simulation is $-4.7 \mathrm{~mm} / \mathrm{ms} 2$, and a value of $3.7 \mathrm{~mm} / \mathrm{ms} 2$ is given by the proposed method. The predictions made by the condensation method and the two-step method are $-2 \mathrm{~mm} / \mathrm{ms} 2$ and $-6 \mathrm{~mm} / \mathrm{ms} 2$ respectively.

Figure 12 shows the v-m stress (effective stress) of concrete element E1. It is clear that, soon after the blast loading phase, the stress within this element quickly mounts up to a peak around $10 \mathrm{MPa}$. The proposed method and two step model well predicts the maximum stress. The condensation method slightly overestimates the peak value probably because the structural mass is condensed to the remaining structure. The concentrated structural mass results in a concentrated gravity load in the remaining structure and thus causes a relatively larger acceleration, velocity and displacement. All three simplified methods predict the damage of concrete material in this element which results in the erosion of this element and leads to the stress in this element quickly dropping to zero.
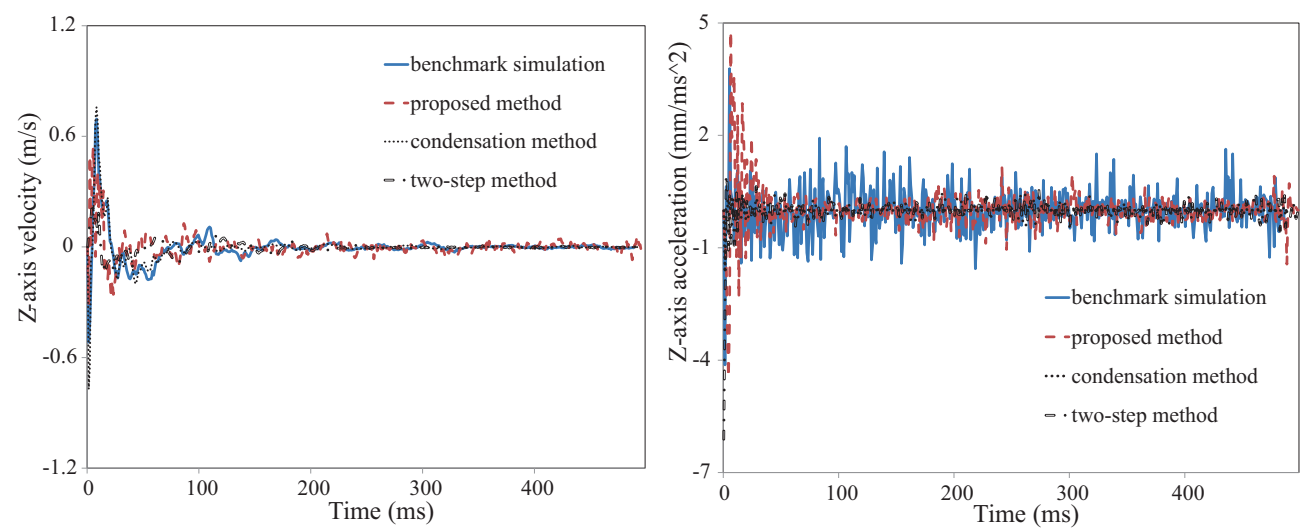

Figure 11. Vertical velocity and acceleration of N1 


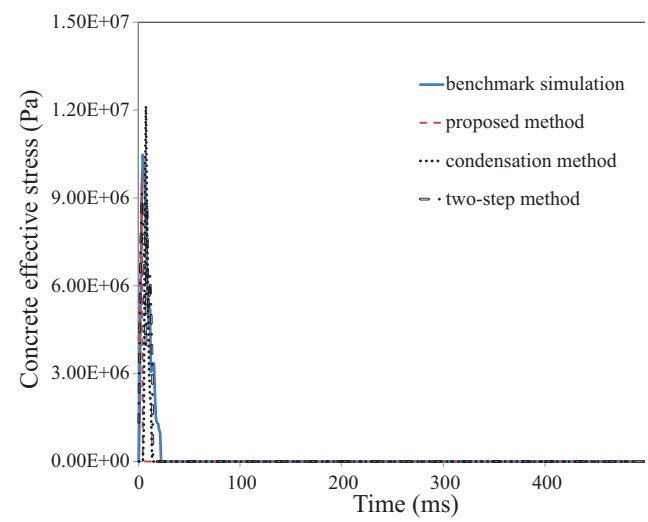

Figure 12. Concrete effective stress of El

Figure 13 shows the axial stress in reinforcement element E2. It is noticed that the maximum axial stress is around $42 \mathrm{MPa}$, and this value is reached at time $20 \mathrm{~ms}$, after $0.5 \mathrm{~s}$ simulation the residual stress is around $16 \mathrm{MPa}$. The proposed method gives a slightly underestimated peak value of $39 \mathrm{MPa}$. The condensation method gives a better fitted time history curve although it overestimates the peak value as $50 \mathrm{MPa}$. The peak value predicted by the two-step method is $37 \mathrm{MPa}$. All the methods predict no damage to this reinforcement element under the considered explosion scenario.

Figure 14 shows the axial stress in the longitudinal reinforcement element E3. The stress in E3 is smaller than that in E2. This is because the axial deformation in the reinforcement element E2 is along the vertical direction and is influenced by the blast load and gravity load. For axial stress in E3, because no clear damage occurs in the column on the ground floor, the reinforcement deformation in the adjacent beams is quite limited, which leads to small axial deformation in E3.

As can be observed, the time history curve provided by the condensation method fits well with the benchmark results at the very beginning of the simulation, and the peak value which is around $24 \mathrm{MPa}$ has been well captured. For the two-step method and the proposed method, their response time-history curves do not exactly follow that obtained by the direct FE simulation, probably because the response induced by the stress wave in direct FE simulation is not modeled in the simplified calculation. However, the peak value, which is the most critical parameter for design, is well captured.

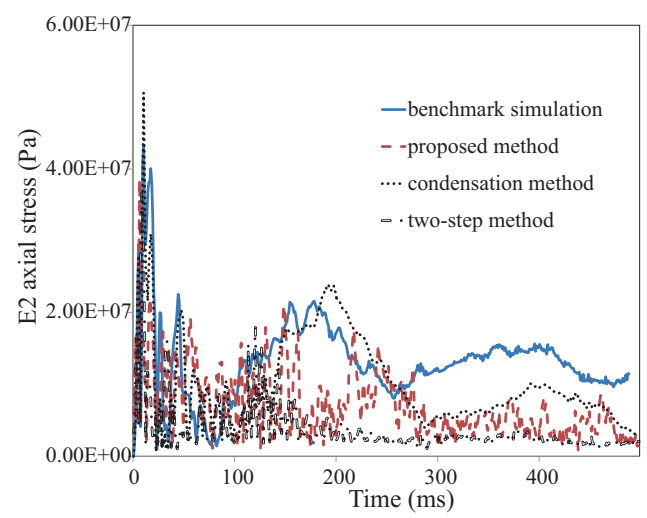

Figure 13. Reinforcement axial stress of E2 


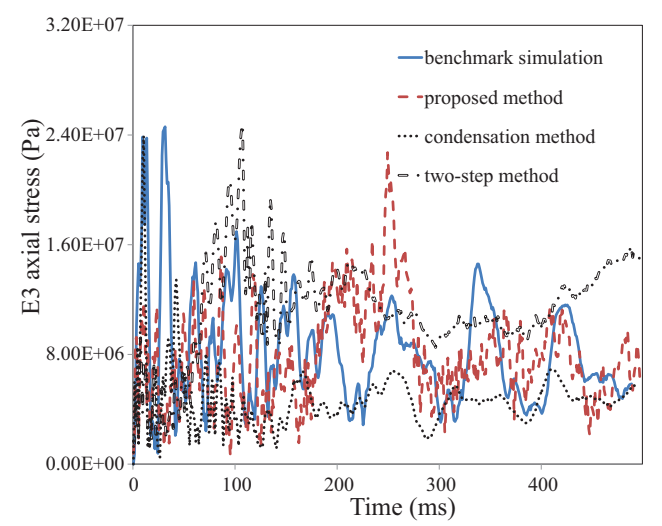

Figure 14. Reinforcement axial stress of E3

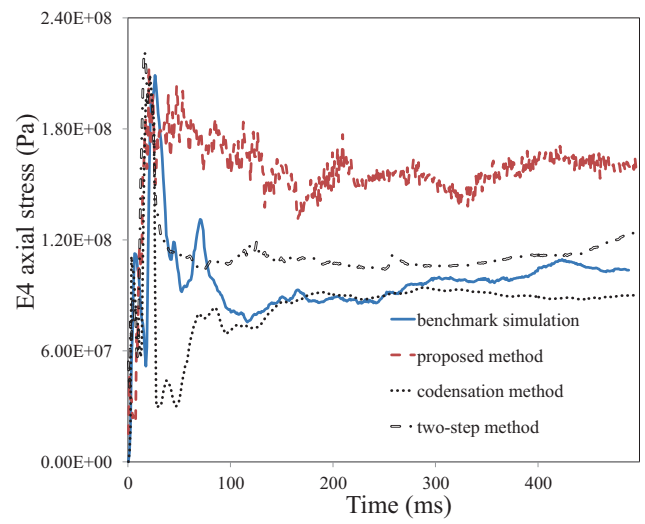

Figure 15. Reinforcement axial stress and strain of E4

Figure 15 shows the comparison of the axial stress time-histories in the stirrup reinforcement element E4 obtained by all approaches. As shown, all the simplified methods well predict the peak value which is around $200 \mathrm{MPa}$. The condensation method and the twostep method also capture the after-peak stress with reasonable accuracy. However, the proposed method over predicts the after-peak stress.

\subsection{CASE STUDY 2}

The observations shown in case study 1 indicate that the proposed method can provide reasonable predictions of structural responses, especially the peak responses when the structure survives the blast loads that collapse does not occur. In this case study, a blast scenario which initiates the progressive collapse is taken into consideration. The blast effect is derived from a $1000 \mathrm{~kg}$ TNT detonated from $12 \mathrm{~m}$ away. The blast loads considered in this case are listed in Table 3.

Table 3. Blast loads and durations on columns

\begin{tabular}{llll} 
& $\begin{array}{l}\text { Middle column of } \\
\text { first floor }\end{array}$ & $\begin{array}{l}\text { Middle column of } \\
\text { second floor }\end{array}$ & $\begin{array}{l}\text { Side column of } \\
\text { first floor }\end{array}$ \\
\hline Blast load & $4.5 \mathrm{MPa}$ & $3 \mathrm{MPa}$ & $2 \mathrm{MPa}$ \\
Duration & $6.7 \mathrm{~ms}$ & $7 \mathrm{~ms}$ & $7.7 \mathrm{~ms}$ \\
\hline
\end{tabular}




\subsubsection{Benchmark simulation}

Figure 16 shows the structural response at $\mathrm{t}=7 \mathrm{~ms}$ which is approximately the end of the blast loading duration. It can be observed that local damage occurs at the middle span on the middle column on the ground floor.

Figure 17 shows the structural response at the end of $t=0.5 \mathrm{~s}$, at this time the collapse of the frame structure is initiated.

\subsubsection{Model condensation method}

Following the same procedure as described in case study 1 , model condensation simulation is again carried out. It can be clearly observed from Figure 18 that the model condensation method well reproduced the structural response at different time instants as compared to the direct FE simulation shown in Figures 16 and 17. Both the local damage and global response have been captured.

\subsubsection{Two-step method}

In this case study, according to the P-I curve diagram, the damage of the middle column on the ground floor is larger than 0.5 , and a conservative value of $\mathrm{D}=0.5$ is used for this column. For the middle column on the first floor, the damage severity is easily obtained as 0.45 . The shear damage zone lengths for these two columns are $1.2 \mathrm{~m}$ and $1.0 \mathrm{~m}$ respectively.

As displayed in Figure 19, the two-step method captures the global deformation shape. However the local crushing damage on the middle of the column on the ground floor is not well

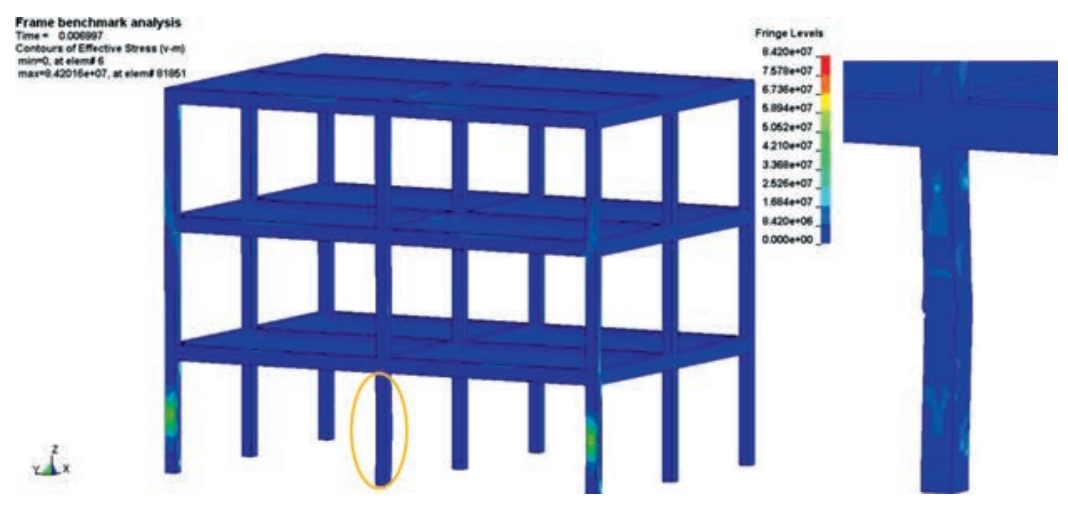

Figure 16. Structural response at the end of blast loading phase

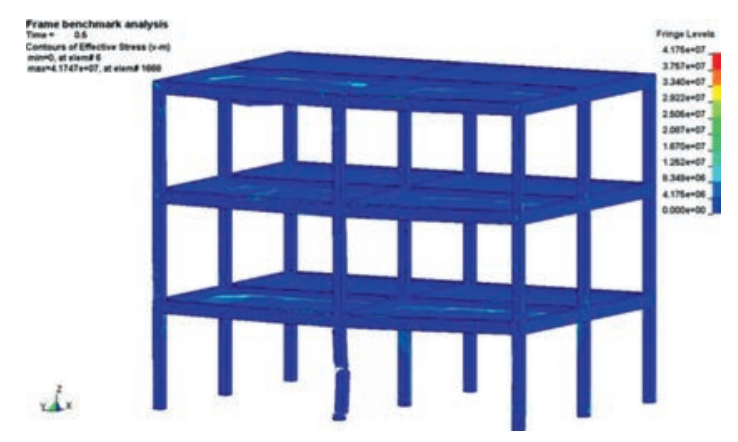

Figure 17. Structural response at $\dagger=500 \mathrm{~ms}$ 

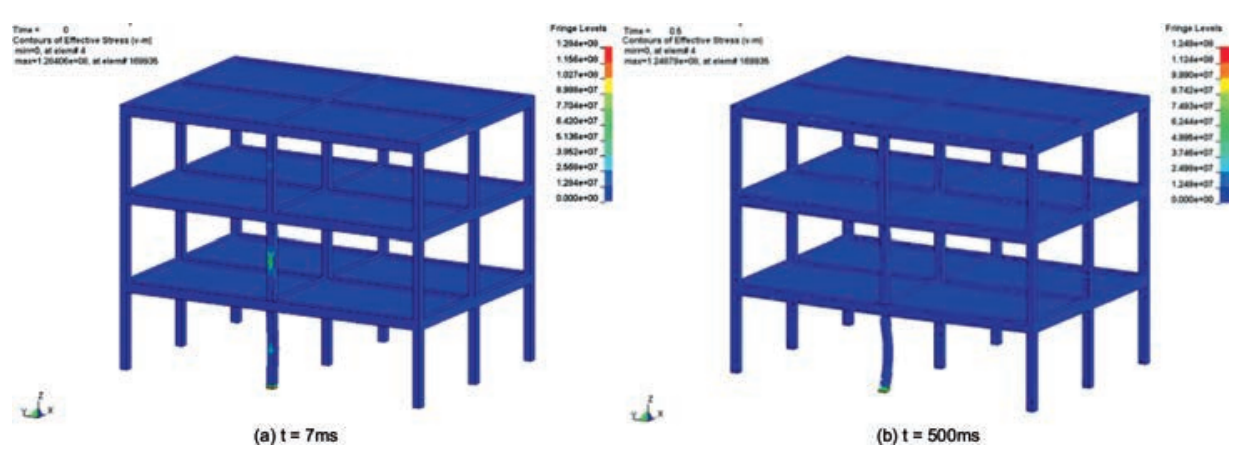

Figure 18. Structural response
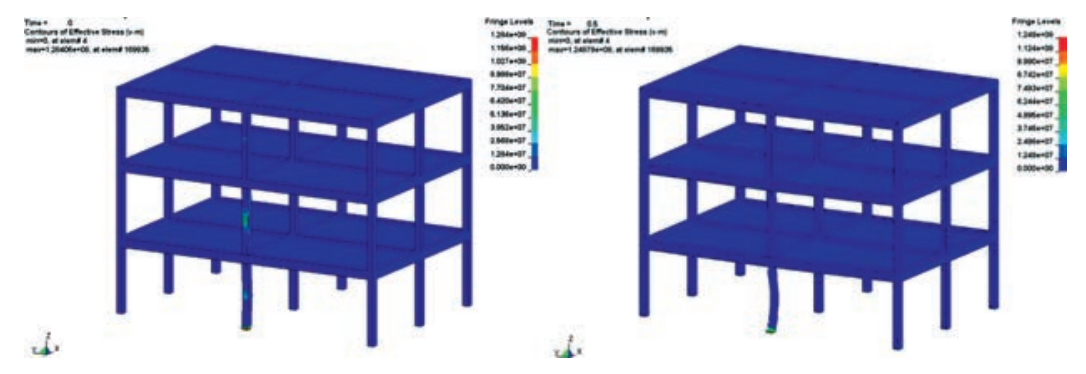

Figure 19. Structural response

simulated although collapse of the middle column is also observed owing to damage at the both ends of the column. This difference can be attributed to the selection of deflection shape in deriving the equivalent SDOF model. In this study, a shear deformation shape as shown in Figure 1 is assumed and the simulated damage also follows this deflection. However, the damage simulated by direct FE model indicates that flexural response mode generates significant damage at the middle height of the column. Nonetheless, as will be demonstrated later the two-step method well captures the overall collapse response of the structure.

\subsubsection{Proposed method}

The proposed method which combines the two-step method and the dynamic condensation is utilized to calculate the structural response. Figure 20a shows the structural response at the end of the blast loading duration. Figure $20 \mathrm{~b}$ shows the structural response at $0.5 \mathrm{~s}$. It can be

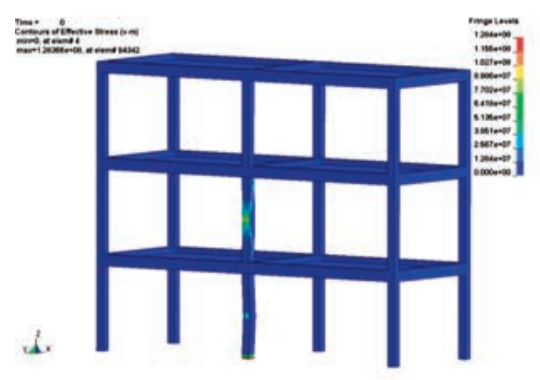

(a) $\mathrm{t}=7 \mathrm{~ms}$

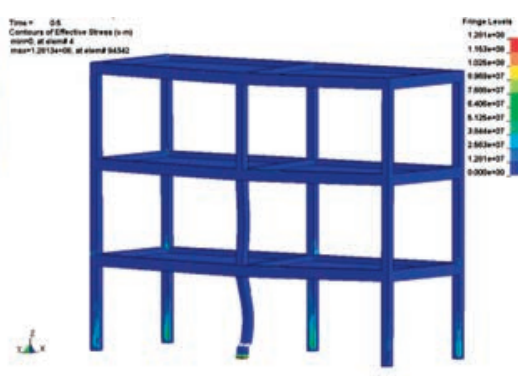

(b) $\mathrm{t}=500 \mathrm{~ms}$

Figure 20. Structural response of the simplified model 
observed the simplified method captures the major deformation shape at these two different time instants. However, it can also be noticed that the damage at the mid span is not simulated either owing to the reason discussed above.

\subsubsection{Quantitative results comparison}

The vertical displacement at node N1 is shown in Figure 21. It can be seen that the node N1 in direct FE and condensed model simulation keeps going downward throughout the whole calculation time. This node in the proposed method and the two-step method experiences slight oscillation at around $150 \mathrm{~ms}$ before continues to going downward. This fluctuation can be explained by the local crushing damage by blast loads applied on the structure which is not well predicted by the SDOF model and the subsequent free vibration analysis. Although the damage at the end of blast loading duration is calculated and introduced into the model, at this stage the damage is more local material damage rather than structural damage. At the end of the simulation time, the residual displacement predicted by the benchmark simulation is about $0.1 \mathrm{~m}$, and the two-step method and proposed method successfully predict this value. The condensation method yields a better time-history curve although the residual displacement has been overestimated.

Figure 22 shows the velocity and acceleration response of node N1 in the vertical direction. In this case, the middle column on the ground floor fails during the simulation, and catenary effect of the two beams on both sides of the column generates a resisting force and therefore reduces the velocity and acceleration. For velocity comparison, the benchmark simulation yields a maximum velocity of $-1.0 \mathrm{~m} / \mathrm{s}$, the results from the two-step method and the proposed method are $-0.9 \mathrm{~m} / \mathrm{s}$ and $-1.1 \mathrm{~m} / \mathrm{s}$ respectively, the time-history curve from the condensation method fits well with the benchmark simulation.

For acceleration comparison, the benchmark simulation yields a maximum value of -4 $\mathrm{mm} / \mathrm{ms} 2$. The proposed method gives reasonably predictions, and the two-step method and condensation method underestimates the peak value.

Figure 23 shows the v-m stress (effective stress) of concrete element E1. It can be observed that after the blast loading phase, the stress experiences a steep decrease owing to the concrete material damage in this element. All the simplified methods successfully predict the peak value which is around 4.3 $\mathrm{MPa}$. It should be noted that the stress predicted in this

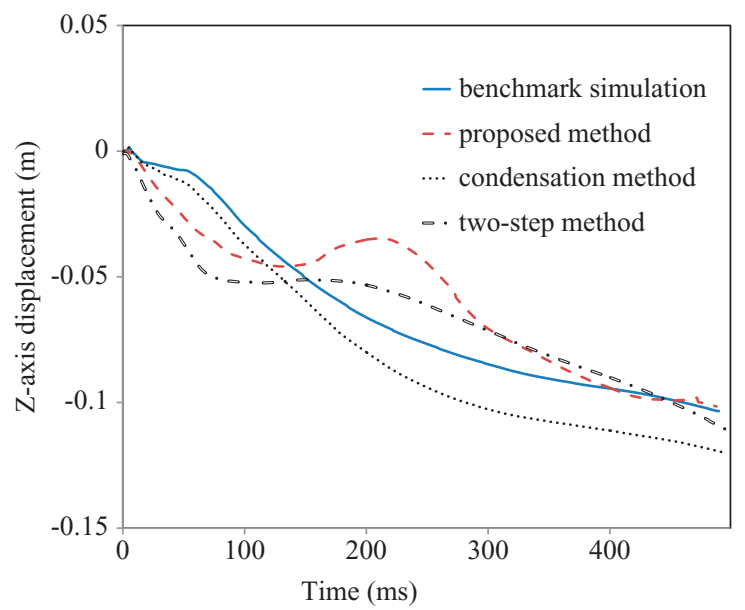

Figure 21. Vertical displacement of N1 

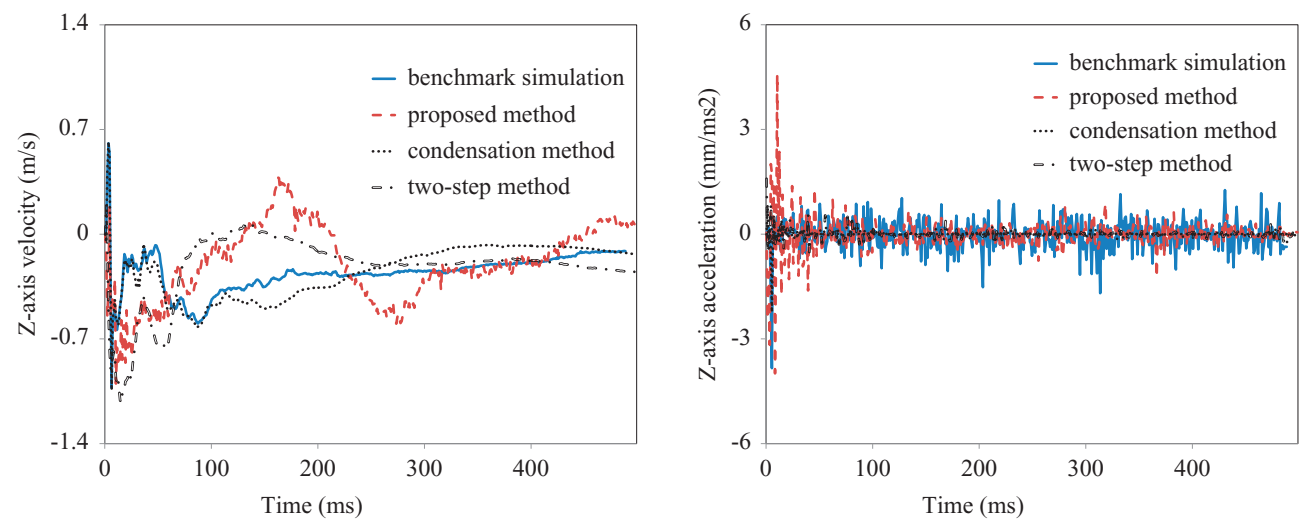

Figure 22. Vertical velocity and acceleration of N1

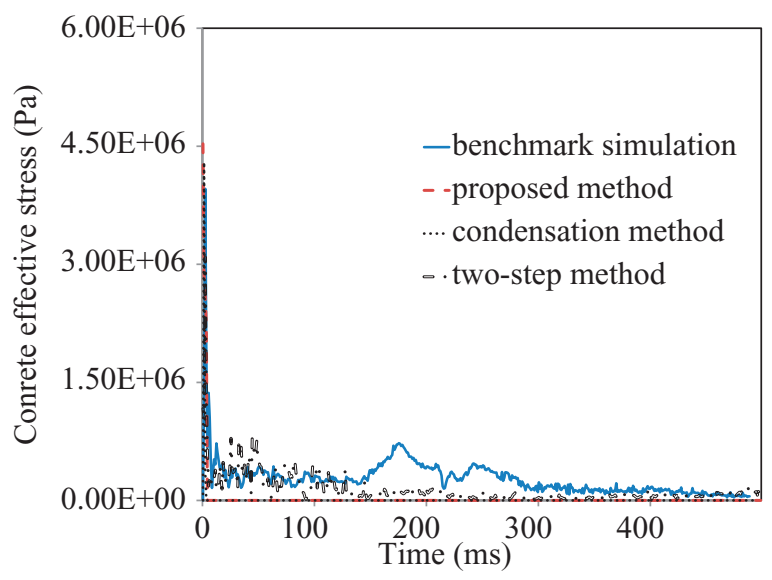

Figure 23. Concrete effective stress of El

element under this large explosion scenario is smaller than that shown in Figure 12 under a relatively smaller blast load. This is because the damage of the supporting concrete column and progressive collapse relive some of the stress in this element and make the element move downward as a rigid body.

Figure 24 shows the axial stress of reinforcement element E2. After the blast loading duration, the axial stress quickly increases to peak value of about $120 \mathrm{MPa}$, then under the resistance force from both the inertia effect and the catenary effect, the stress drops back slightly. After the initiation of the progressive collapse, the axial stress increases again after $0.3 \mathrm{~s}$. The residual stress at the end of simulation is about $90 \mathrm{MPa}$. Although all the three simplified methods give good predictions of the peak axial stress in E2, the residual stress is not well predicted owing to neglecting of the stress wave propagation in the simplified method. The proposed method gives a relatively closer prediction which is around $80 \mathrm{MPa}$.

Figure 25 shows the axial stress within the longitudinal reinforce element E3. Since clear damage occurs in the middle column on the ground floor, the reinforcement deformation in the adjacent beams is not restrained which generates larger stress in element E3 as compared with that in case 1 . 


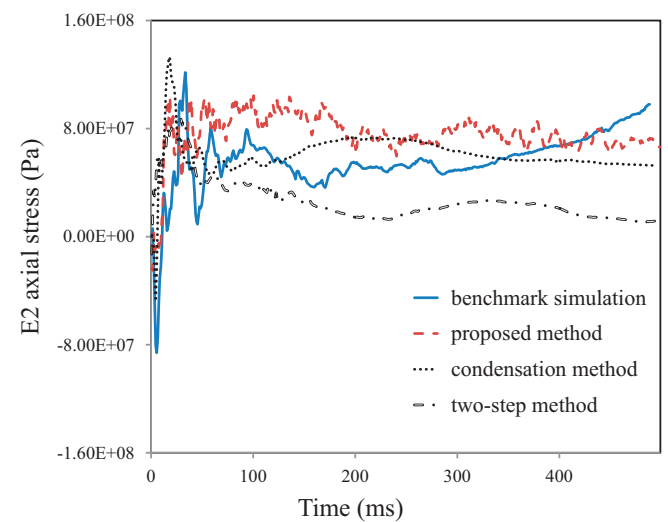

Figure 24. Reinforcement axial stress of E2

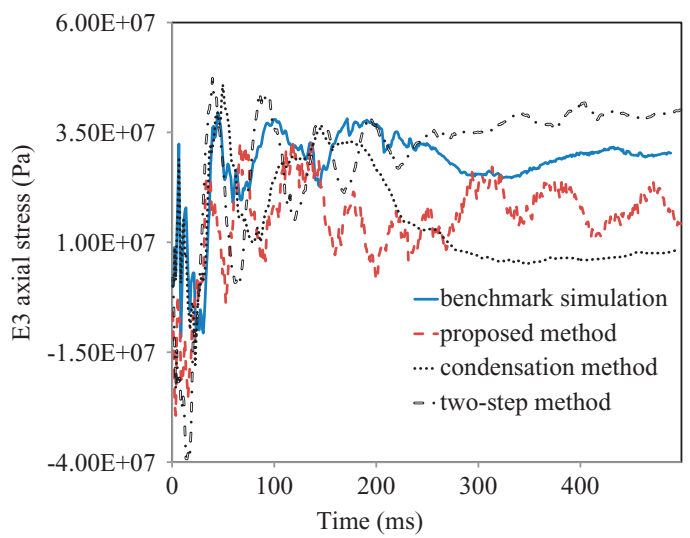

Figure 25. Reinforcement axial stress of E3

As can be observed from the comparison, the condensation method successfully predicts the time-history curve in the first $50 \mathrm{~ms}$. It gives a peak value of $45 \mathrm{MPa}$, which is larger than $38 \mathrm{MPa}$ from the benchmark results. The two-step method gives similar peak stress predictions, but overestimates the residual stress. For the proposed method, it underestimates the residual stress at the end of simulation although the peak prediction is reasonable. This is because the stress generated in the beam elements during the loading phase is not considered in the simulation. In the current study, only the displacement, velocity and damage of a few selected columns induced by blast loading in the loading phase are considered in the second step free vibration analysis.

Figure 26 shows the axial stress within the stirrup reinforcement element E4. In the benchmark simulation, the axial stress drops into a plateau after quickly mounts up to 450 MPa. Similar observations are also obtained by all the three simplified methods. As shown, both the peak and residual stress have been well captured. Generally speaking, all the methods give accurate prediction to the axial stress in reinforcement E4.

The above results indicated that the proposed method gives good predictions of stresses in elements alone the center column (E1, E2 and E4), but relatively inaccurate prediction of stress in beam element E3. This is probably because in the study, only the structural response and damage of a few selected columns are considered in the two-step method as initial 


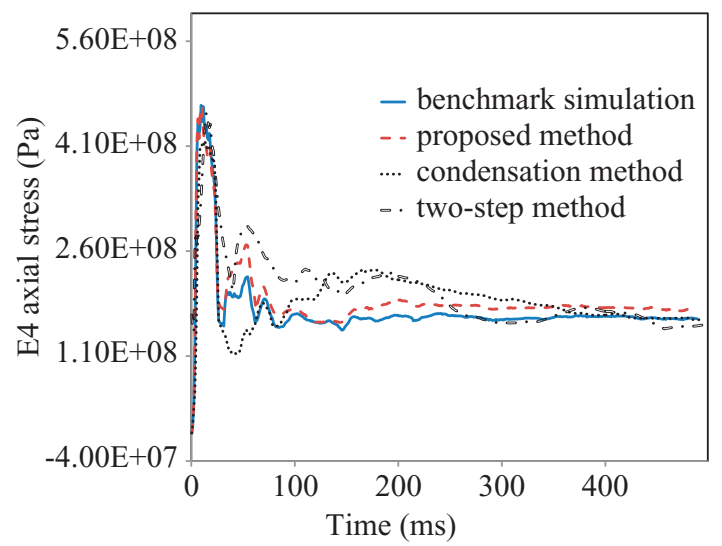

Figure 26. Reinforcement axial stress of E4

conditions in the second step free vibration analysis. The stress generated in the beam elements in the blast loading duration by direct FE and the condensed model simulations are not considered. This leads to some simulation errors. Moreover, as can be noted in the results presented above, although the simplified method successfully predicts peak stresses in the structure, its prediction on stress time histories is not very good, and the prediction accuracy on stress time histories further deteriorate when the stress are relatively small. This is because application of blast loads to the structure in direct FE simulations also generates a stress wave propagating in the structure. This stress wave propagation is not modeled in the two-step method as the two-step method only captures the global element responses. When stress generated by the global response in structural element is small and comparable to stress wave induced by direct blasting loads, the prediction accuracy of stress in reinforce element is therefore not very good. Nonetheless, the two-step method successfully captures the overall structural response and collapse. It also gives good stress predictions when the response is governed by the structural element bending and/or shear responses. The proposed method well captures the peak and residual stresses in column elements, as well as the overall performance, especially collapse of the frame structure.

\subsection{COMPUTATIONAL TIME}

The numerical simulations presented above are all carried out on a desktop computer with $3.16 \mathrm{GHz}$ CPU frequency and $3 \mathrm{G}$ memory. The simulation time for the case study are shown in Table 4.

As shown, the simplified methods all greatly reduce the computation time. When compared with the previously proposed simplified method, i.e. condensation method and the two-step method, combination of the two simplified methods further reduces the calculation effort. In general, the combined method proposed in this study saves more than

Table 4. Time consumption for case studies

\begin{tabular}{lllll} 
& Benchmark & $\begin{array}{l}\text { Condensation } \\
\text { method }\end{array}$ & $\begin{array}{l}\text { Two-step } \\
\text { method }\end{array}$ & $\begin{array}{l}\text { Proposed } \\
\text { method }\end{array}$ \\
\hline Case 1 & $50 \mathrm{~h}$ & $24 \mathrm{~h}$ & $15 \mathrm{~h}$ & $9 \mathrm{~h}$ \\
Case 2 & $60 \mathrm{~h}$ & $28 \mathrm{~h}$ & $18 \mathrm{~h}$ & $11 \mathrm{~h}$ \\
\hline
\end{tabular}


$80 \%$ computational time. Moreover, the proposed method requires substantially less internal memory and storage space as compared to the direct FE modeling. It should also be noted that further reduction of computational effort is expected if a larger structural model is considered. The above results demonstrated that the proposed method can reasonably predict the overall response, progressive collapse and the peak and residual stress of reinforcement bars in RC columns at a significant reduced computational cost. It has a promising application to perform numerical simulations of structural responses to blast loads.

\section{CONCLUDING REMARKS}

The method discussed in this study is aimed to provide a time-saving yet reliable procedure for assessing the blast induced structural dynamic response. It combines the recently proposed two- step and the dynamic condensation method in structural response predictions. Through the two case studies of a three story RC frame structure to blast loads, it is concluded that, compared with the direct FE simulation, the proposed method can give reasonable response predictions. It well captures the overall structural displacement response, progressive collapse and the peak and residual stresses of reinforcement bars in RC beam and columns. The proposed method substantially reduces the computational time and computer memory requirements. It can be used for structural analysis and design under extreme loads.

\section{REFERENCE}

[1] Smith PD, Mays GC, Rose TA, Teo KG, Roberts BJ. Small scale models of complex geometry for blast overpressure assessment. International Journal of Impact Engineering. 1992;12:345-60.

[2] Maji A, Brown J, Urgessa G. Full-Scale Testing and Analysis for Blast-Resistant Design. Journal of Aerospace Engineering. 2008;21:217-25.

[3] Schenker A, Anteby I, Gal E, Kivity Y, Nizri E, Sadot O et al. Full-scale field tests of concrete slabs subjected to blast loads. International Journal of Impact Engineering. 2008;35:184-98.

[4] Yi W-J, He Q-F, Xiao Y, Kunnath SK. Experimental study on progressive collapse-resistant behavior of reinforced concrete frame structures. ACI Structural Journal. 2008;105:433-9.

[5] Fardis MN, Rakicevic ZT, Tsitos A, Mosqueda G. Experimental Investigation of the Progressive Collapse of a Steel Special Moment-Resisting Frame and a Post-tensioned Energy-Dissipating Frame. Role of Seismic Testing Facilities in Performance-Based Earthquake Engineering: Springer Netherlands. p. 367-82.

[6] Assadi-Lamouki A, Krauthammer T. An explicit finite difference approach for the Mindlin plate analysis. Computers \& Structures. 1989;31:487-94.

[7] Lu Y, Gong S. An analytical model for dynamic response of beam-column frames to impulsive ground excitations. International Journal of Solids and Structures. 2007;44:779-98.

[8] AUTODYN. Interactive non-linear dynamic analysis software, version 4.2, user's manual. Century Dynamics Inc. 2001.

[9] Luccioni BM, Ambrosini RD, Danesi RF. Analysis of building collapse under blast loads. Engineering Structures. 2004;26:63-71.

[10] Zhou XQ, Kuznetsov VA, Hao H, Waschl J. Numerical prediction of concrete slab response to blast loading. International Journal of Impact Engineering. 2008;35:1186-200.

[11] Xu K, Lu Y. Numerical simulation study of spallation in reinforced concrete plates subjected to blast loading. Computers \& Structures. 2006;84:431-8.

[12] LS-DYNA. Keyword user's manual. Livermore Software Technology Corporation. Livermore(California); 2006.

[13] Mutalib AA, Hao H. Development of P-I diagrams for FRP strengthened RC columns. International Journal of Impact Engineering. 2011;38:290-304. 
[14] Mutalib A, Hao H. Numerical Analysis of FRP-Composite-Strengthened RC Panels with Anchorages against Blast Loads. Journal of Performance of Constructed Facilities. 2011;25:360-72.

[15] Hao H, Wu C, Li Z, Abdullah AK. Numerical analysis of structural progressive collapse to blast loads. Transactions of Tianjin University. 2006;12:31-4.

[16] Administration GS. Progressive collapse analysis and design guidelines for new federal office buildings and major modernization projects. 2003.

[17] Defence Do. Design of buildings to resist progressive collapse. Unified Facilities Criteria. 2005.

[18] Shi Y, Li Z-X, Hao H. A new method for progressive collapse analysis of RC frames under blast loading. Engineering Structures.32:1691-703.

[19] Tang EKC, Hao H. Numerical simulation of a cable-stayed bridge response to blast loads, Part I: Model development and response calculations. Engineering Structures.32:3180-92.

[20] Hao H, Tang EKC. Numerical simulation of a cable-stayed bridge response to blast loads, Part II: Damage prediction and FRP strengthening. Engineering Structures.32:3193-205.

[21] Riedel W, Mayrhofer C, Thoma K, Stolz A. Engineering and Numerical Tools for Explosion Protection of Reinforced Concrete. International Journal of Protective Structures.1:85-102.

[22] Krauthammer T, Bazeos N, Holmquist T. Modified SDOF Analysis of RC Box-Type Structures. Journal of Structural Engineering. 1986;112:726-44.

[23] Krauthammer T, Shanaa HM, Assadi A. Response of Structural Concrete Elements to Severe Impulsive Loads. Computers \& Structures. 1994;53:119-30.

[24] Hao H. A Simple Numerical Approach to Predict Structure Responses to Blast Loading. First International Conference on Protective Structures. Manchester UK2011. p. 6.

[25] Li J, Hao H. A Two-step Numerical Method for Efficient Analysis of Structural Response to Blast Load. International Journal of Protective Structures.2:103-26.

[26] Li J, Hao H. Influence of Brittle Shear Damage on Accuracy of the Two-Step Method in Prediction of Structural Response to Blast Loads. International Journal of Impact Engineering.

[27] Li J, Hao H. Numerical study of structural progressive collapse using substructure technique. Engineering Structures. 2013;52:101-13.

[28] Guyan RJ. Reduction of stiffness and mass matrices. AIAA. 1965; 3(2):380.

[29] Zolghadr Jahromi H, Izzuddin B, Nethercot D, Donahue S, Hadjioannou M, Williamson E et al. Robustness Assessment of Building Structures under Explosion. Buildings. 2012;2:497-518.

[30] Biggs JM. Introduction to Structural Dynamics: McGraw-Hill, New York; 1964.

[31] S.R. L, J.C. C. Evaluation of the blast resistance of metal deck proofs. Proceeding of the fifth Asia-Pacific conference on shock \& impact loads on structures. Changsha, Hunan, China2003.

[32] Fallah AS, Louca LA. Pressure-impulse diagrams for elastic-plastic-hardening and softening single-degree-offreedom models subjected to blast loading. International Journal of Impact Engineering. 2007;34:823-42.

[33] Ma GW, Shi HJ, Shu DW. P-I diagram method for combined failure modes of rigid-plastic beams. International Journal of Impact Engineering. 2007;34:1081-94.

[34] Li QM, Meng H. Pulse loading shape effects on pressure-impulse diagram of an elastic-pastic, single-degreeof- freedom structural model. International Journal of Mechanical Sciences. 2002;44:1985-98.

[35] Sha Y, Hao H. Nonlinear finite element analysis of barge collision with a single bridge pier. Engineering Structures.41:63-76.

[36] Bi K, Hao H, Chouw N. Influence of ground motion spatial variation, site condition and SSI on the required separation distances of bridge structures to avoid seismic pounding. Earthquake Engineering \& Structural Dynamics.40:1027-43.

[37] Tu Z, Lu Y. Evaluation of typical concrete material models used in hydrocodes for high dynamic response simulations. International Journal of Impact Engineering. 2009;36:132-46.

[38] Comité Euro-International du Béton, CEB-FIP Model Code 1990, Redwood Books, Trowbridge, Wiltshire, UK,. 1993. 
[39] Malvar LJ, Crawford JE. Dynamic increase factors for concrete. DTIC Document; 1998.

[40] Malvar LJ. Review of static and dynamic properties of steel reinforcing bars. ACI Materials Journal. 1998;95.

[41] Shi Y, Hao H, Li Z-X. Numerical derivation of pressure-impulse diagrams for prediction of RC column damage to blast loads. International Journal of Impact Engineering. 2008;35:1213-27.

[42] Defence Do. Design of buildings to resist progressive collapse, unified facilities criteria (UFC, 4-023-03). USA. 2009. 